OPEN ACCESS

Edited by:

Guendalina Graffigna, Università Cattolica del Sacro Cuore,

Italy

Reviewed by:

Gabriela Topa,

Universidad Nacional de Educación a

Distancia (UNED), Spain

Krystyna Golonka,

Jagiellonian University, Poland

*Correspondence:

Annamaria Di Fabio adifabio@psico.unifi.it

Specialty section

This article was submitted to

Organizational Psychology,

a section of the journal

Frontiers in Psychology

Received: 24 March 2017 Accepted: 30 September 2017 Published: 23 October 2017

Citation:

Di Fabio A, Palazzeschi $L$ and Bucci O (2017) In an Unpredictable and

Changing Environment: Intrapreneurial Self-Capital As a Key Resource for Life Satisfaction and Flourishing. Front. Psychol. 8:1819. doi: 10.3389/fpsyg.2017.01819

\section{In an Unpredictable and Changing Environment: Intrapreneurial Self-Capital As a Key Resource for Life Satisfaction and Flourishing}

\author{
Annamaria Di Fabio*, Letizia Palazzeschi and Ornella Bucci \\ Department of Education and Psychology, Psychology Section, University of Florence, Florence, Italy
}

The twenty-first century is characterized by an unpredictable and challenging work environment, and the Intrapreneurial Self-Capital (ISC) career and life construct can be seen as a core of individual intrapreneurial resources that enables people to cope with ongoing challenges, changes, and transitions founding innovative solutions when confronted with the constraints imposed by such an environment. The ISC is a challenging construct since it can enhance behavior and attitudes through specific training, unlike personality traits, which are considered substantially stable in the literature. Against this background, the present study examined the relationship between ISC and well-being (hedonic well-being and eudaimonic well-being) controlling for the effects of personality traits. The Big Five Questionnaire (BFQ), the Intrapreneurial Self-Capital Scale (ISCS), the Satisfaction With Life Scale (SWLS), and the Flourishing Scale (FS) were administered to 258 Italian workers. Hierarchical regression analyses showed that ISC explained a percentage of incremental variance beyond that explained by personality traits in relation to both life satisfaction and flourishing. These results indicate that ISC is a key resource for hedonic well-being and eudaimonic well-being and that it offers new research and intervention opportunities.

Keywords: intrapreneurial self-capital (ISC), life satisfaction, flourishing, career construction, life construction, healthy business, healthy organization

\section{INTRODUCTION}

The twenty-first century has so far been characterized by continuous economic challenges, globalization, and instability in the labor market (Savickas, 2011; Guichard, 2013). Occupational prospects are becoming increasingly unpredictable, and it is even more difficult to predict defined and stable life trajectories (Blustein, 2011, 2013; Savickas, 2011; Duffy et al., 2016).

In the face of this unpredictable and challenging environment, organizations try to introduce more innovation (García-Goñi et al., 2007) and workers need to adapt continually to change (Di Fabio and Gori, 2016a). In the current ever-changing world of work (Di Fabio and Kenny, 2016a), workers require the resources to deal with change constructively (Di Fabio and Gori, 2016a).

They can then devise new ways of dealing with challenges and transitions successfully thereby also promoting their own well-being (Zelenski et al., 2008; Van den Heuvel et al., 2010; Di Fabio and Palazzeschi, 2015; Di Fabio and Bucci, 2016). People who see change as an opportunity to learn and grow are far more likely to respond positively to the challenges of postmodern society (Wanberg and Banas, 2000; Van den Heuvel et al., 2013; Di Fabio, 2014; Di Fabio and Gori, 2016a). The great 
benefit of intrapreneurial self-capital (ISC, Di Fabio, 2014), as a core of individual intrapreneurial resources, is that it can assist people cope with frequent changes and transitions by helping them come up with innovative solutions to problems.

\section{Intrapreneurial Self-Capital}

At the same time, ISC represents a challenging career and life construct, a new scale to measure this construct (Di Fabio, 2014), and an intervention in terms of specific training to build and improve the construct (Di Fabio and Van Esbroeck, 2016). The ISC is "a higher order construct containing seven subconstructs: (1) core self-evaluation as positive judgment of oneself in terms of self-esteem, self-efficacy, locus of control, and absence of pessimism (Judge et al., 2003); (2) hardiness as resistance with its three dimensions: commitment, control, and challenge (Maddi, 1990); (3) creative self-efficacy as one's perception of one's ability to solve problems creatively (Tierney and Farmer, 2002); (4) resilience as the perceived ability to cope with adversity adaptively and to use adaptive strategies to deal with discomfort and adversity (Tugade and Fredrickson, 2004); (5) goal mastery as the perceived ability to continuously develop one's own skills (Midgley et al., 2000); (6) decisiveness as the perceived ability to make decisions timeously in any life context (Frost and Shows, 1993); and (7) vigilance as the careful searching for relevant information (Mann et al., 1997)" (Di Fabio, 2014, pp. 100-102). Empirical studies so far have shown a positive relationship between ISC and scholastic success, career self-efficacy, and employability and a negative relationship with difficulties in making career decisions. What makes ISC particularly interesting is that it can be enhanced through specific training (Di Fabio, 2014) unlike personality traits, which are generally regarded as being substantially stable (McCrae and Costa, 1987).

ISC can, in fact, be seen as an individual resource that workers can use to face the uncertainty of the twenty-first century world of work and that can promote "healthy organizations" within a primary prevention perspective (Hage et al., 2007; Di Fabio and Kenny, 2015). In the postmodern era, the role of a positive work environment in enhancing the health and wellbeing of workers is widely recognized (Sparks et al., 2001) and calls for an organizational positive psychology approach in an organization (Tetrick and Peiró, 2012; Snyder et al., 2014; Di Fabio and Kenny, 2015; Di Fabio and Gori, 2016a,b) centered on fostering positive individual resources to promote employee wellbeing and flourishing, resilient workers (Di Fabio and Saklofske, 2014b; Di Fabio and Kenny, 2015; Di Fabio and Maree, 2016). The definition of a healthy organization is fundamental in this approach (De Smet et al., 2007; Grawitch and Ballard, 2016), and a healthy organization can be considered an organization whose culture, climate, and practices generate an environment that promotes employee health and safety as well as organizational effectiveness (Lowe, 2010).

\section{Hedonic and Eudaimonic Well-Being}

In terms of positive psychology (Seligman and Csikszentmihalyi, 2000), two aspects of well-being can be distinguished: hedonic well-being and eudaimonic well-being. Hedonic well-being (Watson et al., 1988) has life satisfaction as a cognitive evaluation component (Diener et al., 1985) and the dominance of positive emotions over negative emotions as an affective evaluation component (Watson et al., 1988).

Eudaimonic well-being refers to the full functioning of the individual (Ryan and Deci, 2001), life meaning, and purposefulness (Waterman et al., 2010). Flourishing refers to social and psychological prosperity and well-being (Diener et al., 2010) and is seen as perceived success in important areas such as relationships, self-esteem, sense of purpose, and optimism.

ISC, as a core of individual intrapreneurial resources, can therefore be regarded as an asset for workers in the twentyfirst century, helping them create innovative solutions when confronted with constraints imposed by the organizational challenging environment. ISC can promote healthy people in terms of both hedonic and eudaimonic well-being (Di Fabio and Gori, 2016c) and consequently also healthy organizations.

\section{Aim and Hypotheses}

The aim of the study was to examine the relationship between intrapreneurial self-capital (ISC) and life satisfaction and flourishing controlling for the effects of personality traits.

The following two hypotheses were formulated.

H1: A positive relationship will emerge between ISC and life satisfaction controlling for the effects of personality traits.

$\mathrm{H} 2$ : A positive relationship will emerge between ISC and flourishing controlling for the effects of personality traits.

\section{MATERIALS AND METHODS}

\section{Participants}

Two hundred and fifty eight Italian workers of different private and public organizations participated in the study. Regarding gender, the $59 \%$ of the participants were men and the $41 \%$ were women. The participants' ages ranged from 29 to 58 years $(M=$ $45.59, S D=9.92$ ).

\section{Measures}

\section{Big Five Questionnaire (BFQ)}

To evaluate personality traits, the Big Five Questionnaire (BFQ; Caprara et al., 1993) was used. The BFQ consists of 132 items with a response format on a 5-point Likert scale ranging from $1=$ Absolutely false to $5=$ Absolutely true. The questionnaire measures five personality traits. The Cronbach's alpha coefficients were 0.81 for Extraversion (example of item: "I think that I am an active and vigorous person"), 0.73 for Agreeableness (example of item: "I understand when people need my help"), 0.81 for Conscientiousness (example of item: "I tend to be very thoughtful"), 0.90 for Emotional stability (example of item: "I do not often feel tense"), and 0.75 for Openness (example of item: "I am always informed about what is happening in the world").

\section{Intrapreneurial Self-Capital Scale (ISCS)}

To evaluate intrapreneurial self-capital, the Intrapreneurial SelfCapital Scale (ISC; Di Fabio, 2014) was used. The ISCS consists of 28 items (e.g., "I am able to deal with most of my problems," "I am able to improve the ideas produced by others," "One of my goals in training is to learn as much as I can") with a response format on a 5 -point Likert scale ranging from $1=$ Strongly agree 
TABLE 1 | Means, standard deviations, and correlations between BFQ, ISCS, SWLS, and FS.

\begin{tabular}{|c|c|c|c|c|c|c|c|c|c|c|}
\hline & $M$ & $D S$ & 1 & 2 & 3 & 4 & 5 & 6 & 7 & 8 \\
\hline 1. BFQ extraversion & 77.06 & 13.30 & - & & & & & & & \\
\hline 2. BFQ agreeableness & 80.76 & 12.47 & $0.50^{\star \star}$ & - & & & & & & \\
\hline 3. BFQ conscientiousness & 81.72 & 12.80 & $0.48^{\star \star}$ & $0.47^{\star \star}$ & - & & & & & \\
\hline 4. BFQ emotional stability & 71.81 & 13.90 & $0.43^{\star *}$ & $0.41^{\star \star}$ & $0.22^{\star *}$ & - & & & & \\
\hline 5. BFQ openness & 83.52 & 12.98 & $0.53^{\star \star}$ & $0.50^{\star \star}$ & $0.40^{* *}$ & $0.38^{\star \star}$ & - & & & \\
\hline 6. ISCS & 103.00 & 14.57 & $0.31^{\star \star}$ & $0.20^{\star \star}$ & $0.18^{\star \star}$ & $0.16^{\star \star}$ & $0.28^{\star \star}$ & - & & \\
\hline 7. SWLS & 24.01 & 6.35 & $0.50^{\star \star}$ & $0.45^{\star \star}$ & $0.38^{\star \star}$ & $0.39^{\star \star}$ & $0.38^{\star \star}$ & $0.44^{\star \star}$ & - & \\
\hline 8. FS & 43.22 & 7.98 & $0.58^{\star \star}$ & $0.50^{\star \star}$ & $0.39^{* *}$ & $0.40^{\star *}$ & $0.50^{\star \star}$ & $0.52^{\star *}$ & $0.64^{\star *}$ & - \\
\hline
\end{tabular}

$N=258 .{ }^{\star *} p<0.01$. BFQ, Big Five Questionnaire; ISCS, Intrapreneurial Self-Capital Scale; SWLS, Satisfaction With Life Scale; FS, Flourishing Scale.

TABLE 2 | Hierarchical regression.

\begin{tabular}{|c|c|c|}
\hline & SWLS & FS \\
\hline & $\beta$ & $\beta$ \\
\hline \multicolumn{3}{|l|}{ Step 1} \\
\hline BFQ extraversion & $0.24^{\star \star}$ & $0.31^{* *}$ \\
\hline BFQ agreeableness & $0.18^{*}$ & 0.11 \\
\hline BFQ conscientiousness & 0.12 & 0.01 \\
\hline BFQ emotional stability & $0.17^{\star}$ & $0.13^{\star}$ \\
\hline BFQ openness & 0.12 & $0.14^{\star}$ \\
\hline Step 2 & $0.32^{\star \star \star}$ & $0.37^{\star \star \star}$ \\
\hline \multicolumn{3}{|l|}{ ISCS } \\
\hline$R^{2}$ step 1 & 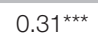 & $0.39^{\star \star \star}$ \\
\hline$\Delta R^{2}$ step 2 & $0.09^{\star \star \star}$ & $0.12^{\star \star \star}$ \\
\hline$R^{2}$ total & $0.40^{\star \star \star}$ & $0.51^{\star \star \star}$ \\
\hline
\end{tabular}

The contributions of personality traits (first step) and intrapreneurial self-capital (second step) to life satisfaction (SWLS) and flourishing (FS).

$N=258 .{ }^{*} p<0.05 .{ }^{\star *} p<0.01 .{ }^{\star * *} p<0.001$. BFQ, Big Five Questionnaire; ISCS, Intrapreneurial Self-Capital Scale; SWLS, Satisfaction With Life Scale; FS, Flourishing Scale.

to $5=$ Strongly disagree. Cronbach's alpha coefficient was 0.84 (Di Fabio, 2014).

\section{Satisfaction with Life Scale (SWLS)}

The Satisfaction With Life Scale (SWLS, Diener et al., 1985) in the Italian version by Di Fabio and Gori (2015) was used to evaluate life satisfaction. The scale consists of five items (e.g., "I am satisfied with my life," "The conditions of my life are excellent") on a 7-point Likert scale ranging from $1=$ Strongly disagree to $7=$ Strongly agree. Cronbach's alpha coefficient was 0.85 .

\section{Flourishing Scale (FS)}

The Flourishing Scale (FS, Diener et al., 2010) in the Italian version by Di Fabio (2016) was used to evaluate flourishing. The FS consists of eight items with response options on a 6-point Likert scale ranging from 1 (Strongly disagree) to 7 (Strongly agree). Examples of items: "My social relationships are supportive and rewarding," "I lead a purposeful and meaningful life," "I am optimistic about my future." The FS showed a unidimensional structure with good reliability in the present study $(\alpha=0.88)$.

\section{Procedure and Data Analysis}

The questionnaires were administered in groups by trained psychologists. The order of administration was counterbalanced to control the possible effects of a set presentation of the instruments.

The study assured to respondents anonymity and confidentiality. The questionnaire included a statement regarding the personal data treatment, in accordance with the Italian privacy law (Law Decree DL-196/2003). The workers authorized and approved the use of anonymous/collective data for possible future scientific publications. Because the data was collected anonymously and the research investigated psycho-social variables not adopting a medical perspective, ethical approval was not sought.

Descriptive statistics, Pearson's $r$ correlations and hierarchical regressions were used. For the studied variables, gender differences were analyzed in distinct regressions for gender but no differences emerged. Therefore, only regressions for the entire sample are presented in the results session.

\section{RESULTS}

Means, standard deviations, and correlations between the BFQ, ISCS, SWLS, and FS are shown in Table 1.

Table 2 shows the results of two different hierarchical regression models, alternatively with life satisfaction and flourishing as the criterion measures and with personality traits at the first step and intrapreneurial self-capital at the second step.

At the first step, personality traits accounted for 31\% of the variance in life satisfaction. At the second step, intrapreneurial self-capital added $9 \%$ of the incremental variance. The model overall accounted for $40 \%$ of the variance.

At the first step, personality traits accounted for 39\% of the variance in flourishing. At the second step, intrapreneurial selfcapital added $12 \%$ of the incremental variance. The model overall accounted for $51 \%$ of the variance.

\section{DISCUSSION}

The aim of the present study was to examine the relationship between intrapreneurial self-capital, life satisfaction and flourishing controlling for the effects of personality traits.

The first hypothesis was confirmed as intrapreneurial selfcapital added significant incremental variance beyond that accounted for by personality traits in relation to life satisfaction. The present study showed that intrapreneurial self-capital helped create individual resources the participants could use to deal 
with twenty-first century challenges and thus also the challenges of everyday existence (Di Fabio, 2014) thereby contributing to greater hedonic well-being in terms of global satisfaction with their own careers and lives (Diener et al., 1985).

The second hypothesis, too, was confirmed as intrapreneurial self-capital added significant incremental variance beyond that accounted for by personality traits in relation to flourishing. These results supported the positive association of intrapreneurial self-capital (Di Fabio, 2014) with eudaimonic well-being (Di Fabio and Gori, 2016c) in terms of social and psychological prosperity and well-being in important areas such as relationships, self-esteem, presence of purpose, and optimism (Diener et al., 2010). It is interesting to note that ISC offered the biggest contribution to variance, especially in relation to flourishing, underlining the promising role of this core of intrapreneurial resources in promoting people as flourishing and resilient workers.

\section{Limitations}

The study showed the positive contribution of ISC to life satisfaction and flourishing, yet a number of limitations can be mentioned. The sample was limited to a group of Italian workers who were not necessarily representative of all Italian workers. Future research should therefore extend the study of the relationship between these variables to participants from different geographical areas in Italy. Participants in other countries could also be included. Future research could also investigate ISC in relation to other aspects of hedonic and eudaimonic well-being (Watson et al., 1988) such as positive affect and meaning in life (Morgan and Farsides, 2009), subjective experiences of eudaimonia (Waterman et al., 2010), and existential fulfillment (Längle et al., 2003). Future research could also investigate ISC in relation to job satisfaction (Drydakis, 2017). Despite these limitations, the results add to the literature on the subject by

\section{REFERENCES}

Blustein, D. L. (2011). A relational theory of working. J. Vocat. Behav. 79, 1-17. doi: 10.1016/j.jvb.2010.10.004

Blustein, D. L. (ed.). (2013). The Oxford Handbook of the Psychology of Working. New York, NY: Oxford University Press.

Boyatzis, R. E. (2009). Competencies as a behavioral approach to emotional intelligence. J. Manag. Dev. 28, 749-770. doi: 10.1108/02621710910987647

Boyatzis, R. E., Batista-Foguet, J. M., Fernández-I-Marín, X., and Truninger, M. (2015). EI competencies as a related but different characteristic than intelligence. Front. Psychol. 6:72. doi: 10.3389/fpsyg.2015.00072

Boyatzis, R. E., and Saatcioglu, A. (2008). A twenty-year view of trying to develop emotional, social and cognitive intelligence competencies in graduate management education. J. Manag. Dev. 27, 92-108. doi: $10.1108 / 02621710810840785$

Boyatzis, R. E., Stubbs, E. C., and Taylor, S. N. (2002). Learning cognitive and emotional intelligence competencies through graduate management education. Acad. Manag. Learn. Educ. 1, 150-162. doi: 10.5465/AMLE.2002.8509345

Caprara, G. V., Barbaranelli, C., and Borgogni, L. (1993). BFQ: Big Five Questionnaire, 2nd Edn. Firenze: Giunti O.S.

De Smet, A., Loch, M., and Schaninger, B. (2007). Anatomy of a healthy corporation. Mckinsey Q. 2, 1-11. underlining the contribution of ISC to life satisfaction and flourishing.

\section{Practical Implications}

If future research confirms the results of the present study, interventions could be introduced to enhance ISC thereby helping people face more successfully the unpredictable and changing environment in twenty-first century organizations. This would promote both individual and organizational wellbeing as seen from a primary prevention perspective in positive psychology (Hage et al., 2007; Di Fabio and Saklofske, 2014b; Di Fabio and Kenny, 2016b).

\section{CONCLUSIONS}

In conclusion, ISC, as a core of individual intrapreneurial strengths, can be regarded as a key resource that workers can use to deal with the ongoing changes in the twenty-first century working environment (Di Fabio, 2014; Di Fabio and Gori, 2016a). The contribution of ISC to different aspects of workers' well-being highlights, from an organizational positive psychology perspective, the importance of enhancing individual resources (Di Fabio and Saklofske, 2014a,b; Di Fabio, 2015) to promote healthy businesses and healthy organizations (Boyatzis et al., 2002, 2015; Boyatzis and Saatcioglu, 2008; Boyatzis, 2009; Di Fabio and Blustein, 2016; Di Fabio and Kenny, 2016a,b; Di Fabio et al., 2016).

\section{AUTHOR CONTRIBUTIONS}

ADF conceptualized the study, choose the theoretical framework and the measures. OB helped in the collection of the data. ADF and LP analyzed the data and wrote the methods and results. Then all authors wrote the paper together and read and revised the manuscript several times.

Diener, E., Emmons, R. A., Larsen, R. J., and Griffin, S. (1985). The satisfaction with life scale. J. Pers. Assess. 49, 71-75. doi: 10.1207/s15327752jpa4901_13

Diener, E., Wirtz, D., Tov, W., Kim-Prieto, C., Choi, D. W., Oishi, S., et al. (2010). New well-being measures: short scales to assess flourishing and positive and negative feelings. Soc. Indic. Res. 97, 143-156. doi: 10.1007/s11205-0099493-y

Di Fabio, A. (2014). Intrapreneurial self-capital: a new construct for the 21 st century. J. Employ. Couns. 51, 98-111. doi: 10.1002/j.2161-1920.2014.00045.x

Di Fabio, A. (2015). Beyond fluid intelligence and personality traits in social support: the role of ability-based emotional intelligence. Front. Psychol. 6:395 doi: 10.3389/fpsyg.2015.00395

Di Fabio, A. (2016). Fluorishing scale: primo contributo alla validazione della versione italiana. [Fluorishing scale: first contribution to the validation of the Italian version]. Counsel. Giornale Ital. Ric. Appl. 9. doi: 10.14605/CS911606

Di Fabio, A., and Blustein, D. L. (eds.). (2016). From Meaning of Working to Meaningful Lives: The Challenges of Expanding Decent Work. Lausanne: Frontiers Media.

Di Fabio, A., and Bucci, O. (2016). Green positive guidance and green positive life counseling for decent work and decent lives: Some empirical results. Front. Psychol. 7:261. doi: 10.3389/fpsyg.2016.00261

Di Fabio, A., Giannini, M., Loscalzo, Y., Palazzeschi, L., Bucci, O., Guazzini, A., et al. (2016). The challenge of fostering healthy organizations: an empirical 
study on the role of workplace relational civility in acceptance of change, and well-being. Front. Psychol. 7:1748. doi: 10.3389/fpsyg.2016.01748

Di Fabio, A., and Gori, A. (2015). Measuring adolescent life satisfaction: psychometric properties of the satisfaction with life scale in a sample of Italian adolescents and young adults. J. Psychoeduc. Assess. 34, 501-506. doi: $10.1177 / 0734282915621223$

Di Fabio, A., and Gori, A. (2016a). Developing a new instrument for assessing acceptance of change. Front. Psychol. 7:802. doi: 10.3389/fpsyg.2016.00802

Di Fabio, A., and Gori, A. (2016b). Assessing Workplace Relational Civility (WRC) with a new multidimensional "mirror" measure. Front. Psychol. 7:890. doi: 10.3389/fpsyg.2016.00890

Di Fabio, A., and Gori, A. (2016c). "Neuroticism and flourishing in white collars workers: from self-esteem to intrapreneurial self-capital for adaptive outcomes," in Neuroticism: Characteristics, Impact on Job Performance and Health Outcomes, ed A. Di Fabio (New York, NY: Nova Science Publishers), 129-146.

Di Fabio, A., and Kenny, M. E. (2015). The contributions of emotional intelligence and social support for adaptive career progress among Italian youth. J. Career Dev. 42, 48-49. doi: 10.1177/0894845314533420

Di Fabio, A., and Kenny, M. E. (2016a). From decent work to decent lives: positive self and relational management (PS\&RM) in the twenty-first century. Front. Psychol. 7:361. doi: 10.3389/fpsyg.2016.00361

Di Fabio, A., and Kenny, M. E. (2016b). Promoting well-being: the contribution of emotional intelligence. Front. Psychol. 7:1182. doi: 10.3389/fpsyg.2016.01182

Di Fabio, A., and Maree, J. G. (2016). Using a transdisciplinary interpretive lens to broaden reflections on alleviating poverty and promoting decent work. Front. Psychol. 7:503. doi: 10.3389/fpsyg.2016.00503

Di Fabio, A., and Palazzeschi, L. (2015). Hedonic and eudaimonic well-being: the role of resilience beyond fluid intelligence and personality traits. Front. Psychol. 6:1367. doi: 10.3389/fpsyg.2015.01367

Di Fabio, A., and Saklofske, D. H. (2014a). Comparing ability and self-report trait emotional intelligence, fluid intelligence, and personality traits in career decision. Pers. Individ. Dif. 64, 174-178. doi: 10.1016/j.paid.2014.02.024

Di Fabio, A., and Saklofske, D. H. (2014b). Promoting individual resources: the challenge of trait emotional intelligence. Pers. Individ. Dif. 65, 19-23. doi: $10.1016 /$ j.paid.2014.01.026

Di Fabio, A., and Van Esbroeck, R. (2016). Intrapreneurial self-capital: a concept fitting a life-designing intervention. Counsel. Giornale Ital. Ric. Appl., 9. doi: $10.14605 /$ CS921611

Drydakis, N. (2017). Trans employees, transitioning, and job satisfaction. J. Vocat. Behav. 98, 1-16. doi: 10.1016/j.jvb.2016.09.003

Duffy, R. D., Blustein, D. L., Diemer, M. A., and Autin, K. L. (2016). The psychology of working theory. J. Couns. Psychol. 63, 127-148. doi: 10.1037/cou0000140

Frost, R. O., and Shows, D. L. (1993). The nature and measurement of compulsive indecisiveness. Behav. Res. Ther. 31, 683-692. doi: 10.1016/0005-7967(93)90121-A

García-Goñi, M., Maroto, A., and Rubalcaba, L. (2007). Innovation and motivation in public health professionals. Health Policy 84, 344-358. doi: 10.1016/j.healthpol.2007.05.006

Grawitch, M. J., and Ballard, D. W. (2016). The Psychologically Healthy Workplace: Building a Win-Win Environment for Organizations and Employees. Washington, DC: American Psychological Association.

Guichard, J. (2013). "Career guidance, education, and dialogues for a fair and sustainable human development," in Inaugural Conference of the UNESCO Chair of Lifelong Guidance and Counselling (Wroclaw: University of Wroclaw).

Hage, S. M., Romano, J. L., Conyne, R. K., Kenny, M., Matthews, C., Schwartz, J. P., et al. (2007). Best practice guidelines on prevention practice, research, training, and social advocacy for psychologists. Couns. Psychol. 35, 493-566. doi: $10.1177 / 0011000006291411$

Judge, T. A., Erez, A., Bono, J. E., and Thoresen, C. J. (2003). The core selfevaluations scale: development of a measure. Pers. Psychol. 56, 303-331. doi: 10.1111/j.1744-6570.2003.tb00152.x

Längle, A., Orgler, C., and Kundi, M. (2003). The existence scale: a new approach to assess the ability to find personal meaning in life and to reach existential fulfillment. Eur. Psychother. 4, 135-146.

Lowe, G. (2010). Creating Healthy Organizations: How Vibrant Workplaces Inspire Employees to Achieve Sustainable Success. Toronto, ON: Toronto University Press.
Maddi, S. R. (1990). "Issues and interventions in stress mastery," in Personality and Disease, ed H. S. Friedman (New York, NY: Wiley), 121-154.

Mann, L., Burnett, P., Radford, M., and Ford, S. (1997). The melbourne decision making inventory: an instrument for measuring patterns for coping with decisional conflict. J. Behav. Decis. Mak. 10, 1-19. doi: 10.1002/(SICI)1099-0771(199703)10:1<1::AID-BDM242>3.0.CO;2-X

McCrae, R. R., and Costa, P. T. (1987). Validation of the five-factor model of personality across instruments and observers. J. Pers. Soc. Psychol. 52, 81-90. doi: $10.1037 / 0022-3514.52 .1 .81$

Midgley, C., Maehr, M. L., Hruda, L. Z., Anderman, E., Anderman, L., Freeman, K. E., et al. (2000). Manual for the patterns of adaptive learning scales. Ann. Arbor. 1001, 48109-41259.

Morgan, J., and Farsides, T. (2009). Measuring meaning in life. J. Happiness Stud. 10, 197-214. doi: 10.1007/s10902-007-9075-0

Ryan, R. M., and Deci, E. L. (2001). "To be happy or to be self-fulfilled: a review of research on hedonic and eudaimonic well-being," in Annual Review of Psychology, ed S. Fiske (Palo Alto, CA: Annual Reviews), 141-166.

Savickas, M. L. (2011). Career Counseling. Washington, DC: American Psychological Association.

Seligman, M. E., and Csikszentmihalyi, M. (2000). Positive Psychology: An Introduction. Washington, DC: American Psychological Association.

Snyder, C. R., Lopez, S., and Teramoto Pedrotti, J. (2014). Positive Psychology: The Scientific and Practical Explorations of Human Strengths. London: Sage.

Sparks, K., Faragher, B., and Cooper, C. L. (2001). Well-being and occupational health in the 21st century workplace. J. Occup. Organ. Psychol. 74, 489-509. doi: 10.1348/096317901167497

Tetrick, L. E., and Peiró, J. M. (2012). "Occupational safety and health," in The Oxford Handbook of Organizational Psychology, Vol. 2, ed S. W. J. Kozlowski (Oxford: Oxford Handbook Online). doi: 10.1093/oxfordhb/9780199928286.013.0036

Tierney, P., and Farmer, S. M. (2002). Creative self-efficacy: its potential antecedents and relationship to creative performance. Acad. Manag. J. 45, 1137-1148. doi: 10.2307/3069429

Tugade, M. M., and Fredrickson, B. L. (2004). Resilient individuals use positive emotion to bounce back from negative emotional experiences. J. Pers. Soc. Psychol. 86, 320-333. doi: 10.1037/0022-3514.86.2.320

Van den Heuvel, M., Demerouti, E., Bakker, A. B., and Schaufeli, W. B. (2010). "Personal resources and work engagement in the face of change," in Contemporary Occupational Health Psychology: Global Perspectives on Research and Practice, Vol. 1, eds J. Houdmont and S. Leka (Chichester: Wiley Blackwell), 124-150.

Van den Heuvel, M., Demerouti, E., Bakker, A. B., and Schaufeli, W. B. (2013). Adapting to change: the value of change information and meaning-making. J. Vocat. Behav. 83, 11-21. doi: 10.1016/j.jvb.2013.02.004

Wanberg, C. R., and Banas, J. T. (2000). Predictors and outcomes of openness to changes in a reorganizing workplace. J. Appl. Psychol. 85:132. doi: 10.1037/0021-9010.85.1.132

Waterman, A. S., Schwartz, S. J., Zamboanga, B. L., Ravert, R. D., Williams, M. K., Bede Agocha, V., et al. (2010). The questionnaire for eudaimonic well-being: psychometric properties, demographic comparisons, and evidence of validity. J. Posit. Psychol. 5, 41-61. doi: 10.1080/17439760903435208

Watson, D., Clark, L. A., and Tellegen, A. (1988). Development and validation of brief measures of positive and negative affect: the PANAS scales. J. Pers. Soc. Psychol. 54, 1063-1070. doi: 10.1037/0022-3514.54.6.1063

Zelenski, J. M., Murphy, S. A., and Jenkins, D. A. (2008). The happyproductive worker thesis revisited. J. Happiness Stud. 9, 521-537. doi: 10.1007/s10902-008-9087-4

Conflict of Interest Statement: The authors declare that the research was conducted in the absence of any commercial or financial relationships that could be construed as a potential conflict of interest.

Copyright $\odot 2017$ Di Fabio, Palazzeschi and Bucci. This is an open-access article distributed under the terms of the Creative Commons Attribution License (CC BY). The use, distribution or reproduction in other forums is permitted, provided the original author(s) or licensor are credited and that the original publication in this journal is cited, in accordance with accepted academic practice. No use, distribution or reproduction is permitted which does not comply with these terms. 